\title{
WILEY-VCH
}

DOI: $10.1002 /(($ please add manuscript number))

Article type: Full Paper

\section{Sunlight Induced Rapid Oil Absorption and Passive Room-Temperature Release: An Effective Solution toward Heavy Oil Spill Cleanup}

Mengchun Wu, Yusuf Shi, Jian Chang, Renyuan Li, Chisiang Ong and Peng Wang*

M. Wu, Y. Shi, J. Chang, R. Li, C. Ong, Prof. P. Wang

Water Desalination and Reuse Center, Division of Biological and Environmental Science and Engineering, King Abdullah University of Science and Technology, Thuwal 23955-6900, Saudi Arabia

E-mail: peng.wang@kaust.edu.sa

Keywords: sunlight, photo-thermal effect, switchable wettability, heavy oil spill, passive oil release

Abstract: Rapid cleanup and easy recovery of spilled heavy oils is always a great challenge due to their high viscosity ( $>10^{3} \mathrm{mPa}$ ). One of the efficient methods to absorb highly viscous oils is to reduce their viscosity by increasing their temperature. In this work, we integrate the sunlight-induced light-to-heat conversion effect of polypyrrole (PPy) and thermo-responsive property of poly(N-isopropylacrylamide) (PNIPAm) into the melamine sponge, which successfully delivers a fast heavy oil absorption under sunlight and passive oil release underwater at room temperature. Thanks to the rationally designed functionalities, the PNIPAm/PPy functionalized sponges possess oleophilicity and hydrophobicity under sunlight. Due to the photo-thermal effect of PPy, the sponges locally heat up contacting heavy oil under sunlight and reduce its viscosity to a point where the oil voluntarily flow into the pores of the sponge. The material in this work is able to rapidly absorb the heavy oil with room temperature viscosity as high as $\sim 1.60 \times 10^{5} \mathrm{mPa}$ s. The absorbed oil can be passively forced out the sponge underwater at room temperature due to the hydrophilicity of PNIPAm. The sunlight responsive and multifunctional sponge represents a meaningful attempt in coming up with a sustainable solution towards heavy oil spill. 


\section{WILEY-VCH}

\section{Introduction}

Accidental oil spills into unintended environment such as sea and rivers are a frequent occurrence in the world and oily wastewaters are commonly produced in many industrial processes. $^{[1-4]}$ The oil spills and oily wastewaters, once produced, demand timely and fast actions to separate oil out of generally bulk water body since dissolution of oil in water as well as spreading of oil slick is a strong function of time. ${ }^{[2,5]}$ A variety of absorbent materials have been developed to remove oil from oil polluted water body, including sponge/foam, ${ }^{[6-11]}$ aerogel, ${ }^{[12]}$ particles, ${ }^{[13,14]}$ etc. However, practical applications of most advanced absorbents has been hampered for heavy oil (viscosity larger than $10^{3} \mathrm{mPa} \mathrm{s}$ ) spills because the diffusion of the highly viscous oils into the inner pores of most absorbents is very slow at room temperature, resulting in a low heavy oil absorption speed and inefficient usage of materials. ${ }^{[11]}$ In-situ burning, dispersant and oil skimmer are frequently used in heavy oil spill accidents, ${ }^{[1,4]}$ but those methods suffer from the drawbacks including air pollution, toxicity to marine lives, inability to recover the heavy oil or limited removal capacities. For conventional oil absorbents, recovery of the absorbed oil and at the same time regeneration of the absorbents are also very challenging. More often, simple physical squeezing, oil evaporation by heating, and combustion at high temperature to burn off the oil are applied to remove the absorbed oils so to regenerate the absorbents, which either are energy intensive, damage the physical structural integrity of the absorbents, or fail to recover the oils efficiently. Therefore, an absorbent capable of fast and effective oil absorption and equally importantly efficient and passive oil release under mild conditions is of great desire.

In recent years, stimuli-responsive absorbents with switchable wettability offer an effective means to absorb and subsequently passively recover oil under external stimuli, such as $\mathrm{pH},{ }^{[15-}$ 20] heat, ${ }^{[21]}$ and UV irradiation ${ }^{[22,23]}$. Among the stimuli-responsive materials, temperature/heat-based switchable material is an interesting case ${ }^{[21,24-30]}$ because of the 


\section{WILEY-VCH}

availability of various direct and indirect heat energy sources, including hot/cold water, electricity used to locally generate heat by Joule heating mechanism. Freely and widely available is another ubiquitous energy source, sunlight, which can be readily harvested and converted to heat by a myriad of solar-thermal materials, ${ }^{[31-35]}$ for instance, metals, ${ }^{[32]}$ carbonbased materials, ${ }^{[3,34]}$ and polymers ${ }^{[35]}$.

In this work, we rationally combine photo-thermal effect with temperature responsive wettability to produce a sunlight driven fast oil removal absorbent. The absorbent captures spilled oil fast and effectively under sunlight and releases the captured oil voluntarily at room temperature underwater. An additional benefit of this material is that, due to the solar-thermal effect of the absorbent, it increases the local temperature of contacting highly viscous oil (heavy oil) and significantly lowers its viscosity, thus making possible a fast and effective adsorption of heavy and even extra heavy oil, which conventional adsorbents are incapable of. The captured heavy oil is able to migrate out of the absorbent automatically by itself underwater at room temperature. Heavy oil or extra-heavy oil with high viscosity $\left(>10^{3} \mathrm{mPa}\right.$ $\mathrm{S}$ at room temperature $)^{[11,36]}$ has been problematic for conventional oil absorbents and the absorbent in this work is the first one of its kind able to effectively capture and passively release heavy oil without further intervention.

Briefly, a sunlight responsive melamine sponge (MS) with switchable wettability was fabricated. The fabrication involved chemical modification of polypyrrole (PPy), poly(Nisopropylacrylamide) (PNIPAm) on MS, with polydopamine (PDA) used as binders to improve the stability of the surface functional groups. ${ }^{[8,14,29,30,37-43]}$ The PPy is sunlight responsive component, enabling the sponge to be heated up as high as $84{ }^{\circ} \mathrm{C}$ under nonconcentrated one sun irradiation $\left(1000 \mathrm{~W} \mathrm{~m}^{-2}\right)$ while PNIPAm provides matching temperature-controlled switchable wettability in the material. ${ }^{[1,24-27]}$ The sponge shows oleopholicity under sunlight and picks up heavy oil quickly by reducing the oil viscosity and it exhibits hydrophilicity at room temperature, resulting in the captured heavy oil voluntarily 


\section{WILEY-VCH}

leaving the sponge. The material reported in this work provides a fast and effective solution towards heavy oil spill cleanup.

\section{Results and Discussion}

\subsection{Fabrication of PNIPAm/PPy@MS}

The process for fabricating solar responsive sponge is schematically presented in Figure 1a. PPy was chosen as the photo-thermal component because of its broad spectrum absorption, high photo-thermal conversion efficiency, and facile solution-based chemical polymerization. ${ }^{[35]}$ To facilitate PPy modification on the MS, the MS was first modified with a binding layer of PDA by in situ polymerization of dopamine monomers in the presence of oxygen as an oxidant and under alkaline condition (denoted as PDA@MS). ${ }^{[37]}$ The scanning electron microscopy (SEM) images in Figure 1b and 1c show that the MS had smooth surface while the surface of PDA@MS was relatively rough with several PDA aggregates clearly recognized (inset of Figure 1c). PPy was then coated onto PDA@MS through in situ chemical polymerization of pyrrole in the presence of $\mathrm{FeCl}_{3}$ as an oxidant. ${ }^{[44]}$ The resulting sponge was denoted as PPy@MS for short. PDA is very adhesive onto MS via hydrogen bonding and $\pi-\pi$ stacking with $\mathrm{MS}^{[37,38]}$ and at the same time is able to form strong hydrogen bonding and $\pi-\pi$ stacking with $\pi$-conjugated polymer chains of PPy, ${ }^{[39,40]}$ leading to a tight anchoring of PPy to the sponge. The uniformly deposited PPy aggregates could be clearly seen on the surface of PPy@MS, which created a dual micro- and nanoscale surface structure and increased the surface roughness of the sponge (Figure 1d). The control experiment without a PDA binding layer showed unevenly distributed PPy aggregates (Figure S1) on MS surface, indicating the necessity of the PDA layer in the synthesis.

The second PDA layer was then introduced onto PPy@MS, followed by the polymerization of PNIPAm layer (denoted as PNIPAm/PPy@MS). Because of the abundant amine and catechol functional groups of PDA, the PDA layer can easily capture NIPAm 


\section{WILEY-VCH}

monomer and act as active sites for the polymerization of NIPAm on the sponge surface and at the same time serve as a cross-linking site to improve the interaction of PNIPAm layer and sponge substrate. ${ }^{[29,30]}$ As a result, a crosslinked PNIPAm layer was coated onto the surface of PPy@MS. As shown in Figure 1e, the micro- and nanoscale rough surface structure was preserved on the surface of PNIPAm/PPy@MS. The rough structure is beneficial to enhance the hydrophobicity of PNIPAm/PPy@MS at the temperature above the lower critical solution temperature (LCST) of PNIPAm. ${ }^{[24,25]}$

The chemical components of the PNIPAm/PPy@MS were verified by Fourier-transform infrared spectroscopy (FTIR) (Figure S2). Compared to the spectrum of MS, the broadened peak at $\sim 3350 \mathrm{~cm}^{-1}$ in the spectrum of PDA@MS can be associated to the -OH of PDA. ${ }^{[29]}$ Typical signals associated with the $\mathrm{C}-\mathrm{H}$ in-plane bending vibration of PPy were found at $\sim 983$ and $\sim 1038 \mathrm{~cm}^{-1[44]}$ and the PNIPAm characteristic signals of $\mathrm{C}=\mathrm{O}$ stretching in amide group and the bending vibrations of isopropyl groups were found at $\sim 1651 \mathrm{~cm}^{-1}$ and $\sim 1455$ $\mathrm{cm}^{-1}$ in the FTIR spectra, respectively. ${ }^{[26,29]}$ The above results confirm a successful synthesis of PNIPAm/PPy@MS.

\subsection{Switchable Wettability of PNIPAm/PPy@MS}

PNIPAm is known to switch between hydrophobicity above its LCST $\left(\sim 32{ }^{\circ} \mathrm{C}\right)$ and hydrophilicity below its LCST, ${ }^{[21,24-30]}$ which has been widely used as thermoresponsive material for controlled oil-water separation. ${ }^{[21,25-27]}$ At the temperature above the LCST, the coiled PNIPAm chains are wrapped by isopropyl groups due to the formation of intramolecular hydrogen bonding among amide groups. At the temperature below the LCST, the stretching PNIPAm chains are wrap-covered by water molecules due to the formation of intermolecular hydrogen bonding between amide groups and water. Contact angle measurements were conducted to probe the wettability of PNIPAm/PPy@MS. In our experiment, at the temperature of $40{ }^{\circ} \mathrm{C}$, PNIPAm/PPy@MS showed hydrophobicity and 


\section{WILEY-VCH}

oleophilicity with a water contact angle of $143^{\circ} \pm 1$ and an oil contact angel of $0^{\circ}$ in air (Figure 2a and 2b), indicating its suitability for oil adsorption. When PNIPAm/PPy@MS was placed under-oil at $40{ }^{\circ} \mathrm{C}$, oil filled sponge can repel water droplets (Figure $2 \mathrm{c}$ and $2 \mathrm{~d}$ ). In contrast, at $22^{\circ} \mathrm{C}$, PNIPAm/PPy@MS showed hydrophilicity with water contact angle of $0^{\circ}$ in air (Figure 2e), while under-oil, water droplet was able to penetrate into and wet oil filled PNIPAm/PPy@MS (Figure 2f). Figure 2g and 2h show that the oil droplets stably stood on the surface of PNIPAm/PPy@MS underwater for an extended time, confirming its hydrophilicity and underwater oleophobicity at $22{ }^{\circ} \mathrm{C}$.

\subsection{Photo-Thermal Property of PNIPAm/PPy@MS}

The light absorption spectra of different sponges are shown in Figure 3a. As can be seen, while the original sponge MS and PDA@MS exhibited weak light absorbance, PPy@MS and PNIPAm/PPy@MS showed strong broadband absorption over the entire solar spectrum with an average absorption of $\sim 99.0 \%$ and $\sim 98.2 \%$ respectivity, owing to the strong and broadband light absorbance of the PPy and the porous structures with the multi-scattering effect. It turns out that the PNIPAm did not noticeably affect the light absorption by the PNIPAm/PPy@MS.

The photo-thermal property of PNIPAm/PPy@MS was investigated by using a simulated solar light $\left(1000 \mathrm{~W} \mathrm{~m}^{-2}\right)$ as light source. The samples $\left(2 \times 2 \times 0.5 \mathrm{~cm}^{3}\right)$ were placed on a thermally insulating expanded polystyrene (EPS) foam board and the measurements were performed at ambient temperature. Figure $3 b$ presents the surface temperature of the samples as a function of irradiation time. The steady state temperatures were $86 \pm 2{ }^{\circ} \mathrm{C}, 84 \pm 2{ }^{\circ} \mathrm{C}, 68$ $\pm 2{ }^{\circ} \mathrm{C}$, and $35 \pm 1{ }^{\circ} \mathrm{C}$ for PPy@MS, PNIPAm/PPy@MS, PDA@MS, and MS, respectively (Figure $3 \mathrm{~b}$ and $3 \mathrm{c}$ ). The steady state temperature was slightly decreased from $86 \pm 2{ }^{\circ} \mathrm{C}$ to 84 $\pm 2{ }^{\circ} \mathrm{C}$ after modification of PNIPAm on the surface of PPy@MS because of the reduced light absorption. The heating rate of PNIPAm/PPy@MS was reduced after modification of PNIPAm. The PPy@MS reached its steady state temperature after $\sim 80$ s sunlight irradiation, 


\section{WILEY-VCH}

while it took 200 s for PNIPAm/PPy@MS to reach its steady state temperature. The reduced heating rate of PNIPAm/PPy@MS was presumably caused by its reduced thermal conductivity (Figure S3) and increased heat capacity. The fact that the steady state temperature of PNIPAm/PPy@MS could reach to $84 \pm 2{ }^{\circ} \mathrm{C}$ under the light irradiation, much greater than the LCST of PNIPAm $\left(\sim 32{ }^{\circ} \mathrm{C}\right)$, allows us to explore the use of PNIPAm/PPy@MS for solar-assisted oil capture.

\subsection{Heavy Oil Absorption Performance of PNIPAm/PPy@MS under Solar Irradiation}

PNIPAm/PPy@MS was first employed to absorb mineral oil floating on the surface of water (Figure 4a). A piece of PNIPAm/PPy@MS $\left(2 \times 2 \times 0.5 \mathrm{~cm}^{3}\right)$ was placed on a thermally insulating EPS foam board under one sun irradiation. After 2 min irradiation, the temperature of PNIPAm/PPy@MS reached to $\sim 84{ }^{\circ} \mathrm{C}$ and the sponge was then used to absorb a floating oil slick on the water surface under light irradiation. The oil was quickly absorbed by the light-heated PNIPAm/PPy@MS upon contact. To assess the oil absorption capacity, PNIPAm/PPy@MS was allowed to absorb oil until saturation and weighted then. As shown in Figure S4, PNIPAm/PPy@MS exhibited good absorption capacity for different oils with low viscosity $(<500 \mathrm{mPa}$ s, Table S1) (e.g., silicone oil, crude oil, mineral oil, and paraffin oil). The maximum absorption capacity was up to $\sim 32$ times its own weight. Due to the low viscosity of these oils, the oil absorption processes were all less than $10 \mathrm{~s}$.

Due to the high adhesion property and resistance to flow of highly viscous oils at room

temperature ${ }^{[11,36,45,46]}$ the absorption of such highly viscous oils into the inner pores of sponge types of oil absorbents is challenging and problematic. One of the efficient methods to absorb highly viscous oils is to reduce their viscosity by increasing their temperature. ${ }^{[1,46]}$ As reported by $\mathrm{Yu}$ and co-works, ${ }^{[11]}$ a Joule-heated absorbent has been fabricated for the high speed absorption of heavy oil by applying an electric current to the graphene coated sponge to heat up the sponge and the surrounding heavy oil spill. Bitumen, which is belonging to extra- 


\section{WILEY-VCH}

heavy oil, ${ }^{[36]}$ was chosen to serve as the highly viscous oil in this work. As shown in Figure $4 \mathrm{~b}$, the viscosity of the bitumen is a strong function with its temperature. The viscosity of bitumen reduced from as high as $\sim 1.60 \times 10^{5} \mathrm{mPa}$ s at room temperature $\left(22^{\circ} \mathrm{C}\right)$ to $\sim 4.71 \times$ $10^{3} \mathrm{mPa} \mathrm{s}$ at $50{ }^{\circ} \mathrm{C}$, representing two orders of magnitude of reduction. The permeating behavior of the bitumen into the PNIPAm/PPy@MS at different temperatures was then investigated. As shown in Figure $4 \mathrm{c}$, when a bitumen droplet $(\sim 5 \mu \mathrm{L})$ was placed on the surface of PNIPAm/PPy@MS at $22{ }^{\circ} \mathrm{C}$, it took $100 \mathrm{~min}$ for the oil to entirely permeate into the PNIPAm/PPy@MS, which was mainly due to the gravitational effect of the bitumen droplet. However, when the PNIPAm/PPy@MS was heated to $50{ }^{\circ} \mathrm{C}$, the whole oil permeating process completed within 1 min, demonstrating a remarkable improvement in the heavy oil absorption speed by increasing the heavy oil temperature.

In order to test the ability of PNIPAm/PPy@MS to heat heavy oil under light irradiation, PNIPAm/PPy@MS and the original MS were placed on the surface of a bitumen layer, which floated on top of a water body. The temperature changes of the sponge top surface and bottom surface of the oil/sponge interface were recorded by IR camera and thermocouple thermometer respectively. As shown in Figure 4d, there was an obviously greater temperature rise with PNIPAm/PPy@MS than the original MS when the light was on. The temperature of PNIPAm/PPy@MS top surface quickly increased to $\sim 70{ }^{\circ} \mathrm{C}$ within $1 \mathrm{~min}$. It is worth pointing out that this temperature of $\sim 70{ }^{\circ} \mathrm{C}$ was lower than the temperature of the same sponge placed on the thermally insulating EPS foam board as previously tested $\left(\sim 84{ }^{\circ} \mathrm{C}\right.$, Figure $\left.3 \mathrm{~b}\right)$ because of the high thermal conductivity of the oil absorbed inside the pores of the sponge. In the entire course of the light irradiation, the top temperature of PNIPAm/PPy@MS $\left(\sim 70{ }^{\circ} \mathrm{C}\right)$ was consistently higher than that of the original MS $\left(\sim 35^{\circ} \mathrm{C}\right)$ due to the excellent light capture capability of PNIPAm/PPy@MS. Meanwhile, the interfacial temperature between PNIPAm/PPy@MS and the contacting bitumen oil increased gradually and reached $\sim 53{ }^{\circ} \mathrm{C}$ after 20 min of light irradiation, which is higher than the temperature of MS/oil interface. The 


\section{WILEY-VCH}

higher top and bottom sponge/oil interface temperatures of PNIPAm/PPy@MS under light irradiation are expected to dramatically reduce the underlying oil viscosity and thus accelerate the heavy oil absorption process.

The solar-assisted bitumen adsorption by PNIPAm/PPy@MS was then performed on a labmade device, which is schematically presented in Figure $4 \mathrm{e}$ and $4 \mathrm{f}$. Briefly, the sponge sample was fixed onto a cantilever which was connected to an electronic balance. A heavy oil container was placed on a moveable stage and the stage was slowly lifted up in the absence of light irradiation until the oil surface contacted with the bottom of sponge. Upon contact, the sample weight jumped sharply due to the adhesive force between the oil and sponge. The formation of a weight plateau after contacting the oil with sponge (10-20 min section in Figure 4f) indicates that the oil did not permeate into the sponge at room temperature in the absence of light irradiation.

The light was turned on at $20 \mathrm{~min}$ to start heavy oil adsorption stage. Upon the light on, the weight of PNIPAm/PPy@MS increased gradually as the oil was being adsorbed into the sponge. After 23 min of light irradiation, the oil absorption of PNIPAm/PPy@MS reached its saturation and a third weight plateau region formed. At last, the stage was gradually moved down until the sponge entirely separated from the oil surface. During this process, the sample weight increased sharply first due to the strong adhesive force between the oil and sponge before decreasing to form a fourth weight plateau region (53-63 min), which was the final sample weight. It was determined that PNIPAm/PPy@MS absorbed 2.05 g highly viscous bitumen oil under light irradiation for $23 \mathrm{~min}$. In comparison, the original MS absorbed only $\sim 0.35 \mathrm{~g}$ of the same oil. In the case of MS, the oil adhered only to the bottom surface and failed to penetrate into the pores of MS (inset of Figure 4f).

The bitumen sample tested above was purposefully selected to have an extremely high viscosity of $\sim 1.60 \times 10^{5} \mathrm{mPa} \mathrm{s}$ at room temperature, which made it a kind of extra-heavy oil. $^{[36]}$ A faster oil absorption kinetic can be expected for the heavy oils with a lower viscosity. 


\section{WILEY-VCH}

In one experiment, the bitumen sample was mixed with paraffin oil to reduce its viscosity to $\sim 2.83 \times 10^{4} \mathrm{mPa}$ s at $22{ }^{\circ} \mathrm{C}\left(\right.$ denoted as bitumen $\left.{ }^{1}\right)$. The absorption process for the bitumen ${ }^{1}$ was completed much faster within 9 min under light irradiation by the same sponge (Figure S5).

\subsection{Passive Oil Release of PNIPAm/PPy@MS Underwater at Room Temperature}

To investigate the oil release and recovery property, PNIPAm/PPy@MS $\left(2 \times 2 \times 0.5 \mathrm{~cm}^{3}\right)$ was first allowed to absorb oils of different types (silicone oil, crude oil, mineral oil, paraffin oil, bitumen ${ }^{1}$ and bitumen) until saturation under light irradiation. The oil saturated sponges were then immersed into the bulk water at room temperature $\left(22^{\circ} \mathrm{C}\right)$. Figure $5 \mathrm{a}$ and Movie S1 show a fully passive mineral oil release process from PNIPAm/PPy@MS. After being immersed in water for 1 min, the mineral oil was released from PNIPAm/PPy@MS drop by drop without any human intervention. After $\sim 13 \mathrm{~min}, \sim 91 \%$ mineral oil was released. This process could be explained as follows. When PNIPAm/PPy@MS is immersed in water at room temperature, the PNIPAm gives the sponge a superhydrophilicity and underwatersuperoleophobicity, which permits water permeation into the sponge via capillary force. The penetrating water gradually forces out the pre-trapped air bubbles along with the pre-absorbed oil in the sponge. The trapped air bubbles by the porous sponge during the oil absorption process play an important role to release the absorbed oils, which can assist the water to permeate the inside of the sponge, and then spontaneously grow and drag the oil droplet to escape from the sponge. ${ }^{[21,22]}$ The expelled oils, once out of the sponge, formed spherical oil droplets, gradually detached from the sponge drop by drop, floated to the surface of water due to its density. This result indicates that the photo-thermal responsive PNIPAm/PPy@MS with switchable wettability is a smart sponge for effective oil absorption and passive desorption.

The highly viscous oils could also be efficiently and automatically released from the PNIPAm/PPy@MS underwater at $22{ }^{\circ} \mathrm{C}$, although with a slower rate. As shown in Figure 5b, 


\section{WILEY-VCH}

the bitumen gradually desorbed out of the sponge and the desorbed bitumen aggregated and formed spherical droplets, many of which adhered on the sponge surface while others were released to the water. The density of this bitumen was $\sim 0.99 \mathrm{~g} \mathrm{~mL}^{-1}$, leading to some bitumen droplets floating on water surface and others sinking down to the bottom of water. After $\sim 14 \mathrm{~h}$, gentle shaking was applied, upon which most bitumen droplets detached from the sponge surface. Then the remaining bitumen droplets could be released to water by gentle knife peeling. Due to the high viscosity of the heavy oil, completely removing the heavy oil from sponges at room temperature is difficult. Yu and co-workers ${ }^{[11]}$ reported a $71 \%$ recovery at $75^{\circ} \mathrm{C}$ and $49 \%$ at $25^{\circ} \mathrm{C}$ for a heavy crude oil with a viscosity of $\sim 5.0 \times 10^{3} \mathrm{mPa}$ s at $22{ }^{\circ} \mathrm{C}$ by compressing the oil-filled absorbents. In this work, we could achieve $\sim 88 \%$ bitumen $\left(\sim 1.60 \times 10^{5} \mathrm{mPa}\right.$ s $)$ recovery by PNIPAm/PPy@MS underwater at $22{ }^{\circ} \mathrm{C}$, which indicates the efficacy of PNIPAm/PPy@MS. The heavy oil desorption process could be accelerated by reducing the oil viscosity. For example, the desorption process for the bitumen ${ }^{1}\left(\sim 2.8 \times 10^{4}\right.$ $\mathrm{mPa}$ ) was completed within $\sim 6 \mathrm{~h}$ (Figure S6). In all cases, the passive oil recovery (i.e., silicone oil, crude oil, mineral oil, paraffin oil, bitumen ${ }^{1}$ and bitumen) by the PNIPAm/PPy@MS was all above 87\% (Figure 5c).

It is worth mentioning that after three cycles of bitumen desorption process, the oil recovery percentage of PNIPAm/PPy@MS decreased to 61\% (Figure S7). Presumably, this is because, at the end of each oil absorption-desorption cycle, a drying process is applied during which the residual bitumen in the sponge gradually wraps onto the sponge fibers' surface, keeping them from being effectively wetted by water. In order to recover the remaining bitumen from PNIPAm/PPy@MS completely, organic solvent (e.g., hexane) washing can be used. After rinsing the sponge by hexane after three oil absorption-desorption cycles, the residual bitumen could be removed completely and the bitumen absorptiondesorption capacities of the sponge could be fully recovered (Figure S7). 


\section{WILEY-VCH}

At last, the mechanical property measurement of PNIPAm/PPy@MS was performed with a universal testing system by compressing the sponge at a set strain of 50\%. As shown in Figure S8a, even though a little deformation of PNIPAm/PPy@MS appeared after 100 cycles of compress-release process, the sponge still maintained its elasticity well. The sponge after 100 cycles of compress-release test still showed satisfactory bitumen desorption property; $\sim 81 \%$ bitumen previously absorbed in the sponge was released after $\sim 16 \mathrm{~h}$ underwater at room temperature (Figure S8b).

\section{Conclusion}

We have demonstrated the fabrication of sunlight-thermal responsive PNIPAm/PPy@MS with switchable wettability. The PNIPAm/PPy@MS exhibits excellent oils absorption property under light irradiation especially for highly viscous oils, which is otherwise impossible with conventional oil absorbents. Meanwhile, the absorbed oils can be automatically desorbed from PNIPAm/PPy@MS underwater at room temperature, which makes it the first to absorb highly viscous oil and to passively recover it effectively. The fabrication of PNIPAm/PPy@MS is technically simple, the oil absorption process involves only sunlight as energy source, the oil recovery process is automatic, requires no energy input, and it does not lead to any structural damage to the absorbents. All of these attractive features make PNIPAm/PPy@MS highly promising for highly heavy oil spill cleanup.

\section{Experimental Section}

Materials: Dopamine hydrochloride, pyrrole, sodium dodecyl benzene sulfonate (SDBS), ammonium persulfate (APS), N-Isopropylacrylamide $\quad$ (NIPAm), N,N'Methylenebisacrylamide (BIS), mineral oil, silicone oil AP 100, silicone oil, and paraffin oil were purchased from Sigma-Aldrich. Ferric chloride $\left(\mathrm{FeCl}_{3}\right)$ and tris(hydroxymethyl)aminomethane (Tris) were purchased from Acros Organics. Crude oil and 


\section{WILEY-VCH}

bitumen were obtained from local store at Thuwal, Saudi Arabia. Melamine sponge was commercially available. All the chemicals were used as received without further purification. Deionized water $(18.2 \mathrm{M} \Omega \mathrm{cm})$ was used for all of the experiments.

Fabrication of PPy@MS: PPy@MS was prepared through successive in situ polymerization of dopamine, ${ }^{[37]}$ and pyrrole monomers ${ }^{[44]}$ on the surface of MS, respectively. Firstly, one piece of MS was immersed in Tris- $\mathrm{HCl}(\mathrm{pH}=8.5,10 \mathrm{mM})$ buffer with $2 \mathrm{mg} \mathrm{mL}^{-1}$ dopamine for $12 \mathrm{~h}$ under stirring to obtain PDA coated MS. The resulting brown PDA coated MS was rinsed with water to remove the physically adsorbed residuals. Then PDA coated MS was soaked in $1.5 \mathrm{mg} \mathrm{mL}^{-1}$ pyrrole aqueous solution with $0.2 \mathrm{mg} \mathrm{mL}^{-1} \mathrm{SDBS}$ under stirring. After the mixture was stirred for $0.5 \mathrm{~h}, 10 \mathrm{~mL} \mathrm{FeCl}_{3}$ aqueous solution (the mole ratio of $\mathrm{FeCl}_{3}$ and pyrrole is 1:1) was dropwise added to initiate the polymerization of pyrrole monomers. The reaction mixture was stirred for $2 \mathrm{~h}$ to obtain black PPy/PDA coated MS, which was then rinsed with water to remove physically adsorbed residuals. The resulting sponge was abbreviated as PPy@MS.

Fabrication of PNIPAm/PPy@MS: Firstly, the second PDA layer was fabricated on the surface of PPy@MS. Then PNIPAm layer was fabricated according to the literature method. ${ }^{[25,29]}$ NIPAm (1 g, monomer), BIS (0.04 g, cross-linker) and APS (0.04 g, initiator) were dissolved in water to form a NIPAm reaction solution. Free-radical polymerization of the NIPAm monomer solution was applied to fabricate the PNIPAm layer on the surface of PDA-coated PPy@MS. After 6 h reaction at 70 ㄷ, PNIPAm coated PPy@MS was obtained. Finally, PNIPAm coated PPy@MS was rinsed with water and dried in an oven at $70{ }^{\circ} \mathrm{C}$, which was abbreviated as PNIPAAm/PPy@MS.

Oil Absorption and Desorption Processes: Four kinds of low viscous oils including silicone oil, crude oil, mineral oil, and paraffin oil were used in this study. Before oil absorption, a piece of PNIPAm/PPy@MS $\left(2 \times 2 \times 0.5 \mathrm{~cm}^{3}\right)$ was placed on a thermally insulating EPS foam board under light irradiation for $2 \mathrm{~min}$. Then the solar-heated sponge was 


\section{WILEY-VCH}

used to absorb the floated oil on water surface under light irradiation. Until all the floated oils were collected or the absorption process reached saturation, the sponge was removed from water surface. The absorption tests of highly viscous oils (bitumen ${ }^{1}$ and bitumen) were performed on a lab-made device (Figure 4e). Oil absorption capacities were calculated by the Equation:

$$
\left(w_{o+s}-w_{s}\right) / w_{s}
$$

Where $w_{o+s}$ represents the weight of the oil filled sponge after oil absorption process, $w_{s}$ represents the weight of original sponge. For the oil desorption tests, the oil filled sponge was immersed underwater at room temperature to release the absorbed oil. After the oil released, the sponge was dried at room temperature. Oil desorption capacities were calculated according to the Equation:

$$
\left(w_{o+s}-w_{r+s}\right) /\left(w_{o+s}-w_{s}\right) \times 100 \%
$$

Where $w_{r+s}$ represents the weight of the sponge with residual oil after oil desorption process.

The Mechanical Compression Test: The mechanical property of PNIPAm/PPy@MS was performed with a universal testing system by compressing the sponge at a set strain of $50 \%$ and a compressing rate of $1 \mathrm{~mm} \mathrm{~s}^{-1}$. Before the compression test, PNIPAm/PPy@MS $(2 \times 2 \times$ $2 \mathrm{~cm}^{3}$ ) was wetted by water, and then the water was removed by centrifugation at $3000 \mathrm{rpm}$ for $5 \mathrm{~min}$. After the compression test, the PNIPAm/PPy@MS $\left(2 \times 2 \times 2 \mathrm{~cm}^{3}\right)$ was cutted into small pieces $\left(2 \times 2 \times 0.5 \mathrm{~cm}^{3}\right)$ for the bitumen absorption-desorption test.

Material Characterization: Scanning electron microscopy (SEM) images were obtained on a Zeiss Merlin FE-SEM. Fourier-transform infrared (FTIR) spectra were measured on a Nicolet iS10 FTIR spectrometer. UV-vis-NIR spectra were measured on an Agilent Cary 5000 UV-Vis-NIR spectrophotometer. Temperature curves and thermal images of the samples were recorded by an FLIR A655 infrared camera. The simulated solar irradiation was provided by a $150 \mathrm{~W}$ Oriel Solar Simulator. Contact angle measurements were performed on a Contact Angle Measuring System DataPhysics OCA 35 by using a $4 \mu \mathrm{L}$ droplet as the 


\section{WILEY-VCH}

indicator. Oil viscosity was measured on a Thermo Scientific HAAKE Viscotester 6 plus. An Oakton thermocouple thermometer with a $0.5 \mathrm{~mm}$ K-type thermocouple sensor was used to monitor the interface temperature. The mechanical compression test was performed on an INSTRON 5944 Universal Testing System.

\section{Supporting Information}

Supporting Information is available from the Wiley Online Library or from the author.

\section{Acknowledgements}

This work was supported by the King Abdullah University of Science and Technology (KAUST) center competitive fund (CCF) awarded to Water Desalination and Reuse Center (WDRC).

Received: ((will be filled in by the editorial staff))

Revised: ((will be filled in by the editorial staff)) Published online: ((will be filled in by the editorial staff))

\section{References}

[1] M. Schrope, Nature 2010, 466, 680.

[2] T. J. Crone, M. Tolstoy, Science 2010, 330, 634.

[3] B. Wang, W. Liang, Z. Guo, W. Liu, Chem. Soc. Rev. 2015, 44, 336.

[4] J. Ge, H. Y. Zhao, H. W. Zhu, J. Huang, L. A. Shi, S. H. Yu, Adv. Mater. 2016, 28, 10459.

[5] J. Chang, L. Zhang, P. Wang, Environ. Sci.: Nano 2018, DOI: 10.1039/C7EN00760D.

[6] F. Chen, Y. Lu, X. Liu, J. Song, G. He, M. K. Tiwari, C. J. Carmalt, I. P. Parkin, Adv. Funct. Mater. 2017, 27, 1702926.

[7] X. Zhang, Z. Li, K. Liu, L. Jiang, Adv. Funct. Mater. 2013, 23, 2881.

[8] C. Ruan, K. Ai, X. Li, L. Lu, Angew. Chem. Int. Ed. 2014, 53, 5556.

[9] S. Chen, G. He, H. Hu, S. Jin, Y. Zhou, Y. He, S. He, F. Zhao, H. Hou, Energy Environ. Sci. 2013, 6, 2435.

[10] H. Bi, X. Xie, K. Yin, Y. Zhou, S. Wan, L. He, F. Xu, F. Banhart, L. Sun, R. S. Ruoff, Adv. Funct. Mater. 2012, 22, 4421. 


\section{WILEY-VCH}

[11] J. Ge, L. A. Shi, Y. C. Wang, H. Y. Zhao, H. B. Yao, Y. B. Zhu, Y. Zhang, H. W. Zhu, H. A. Wu, S. H. Yu, Nat. Nanotechnol. 2017, 12, 434.

[12] C.-B. Ma, B. Du, E. Wang, Adv. Funct. Mater. 2017, 27, 1604423.

[13] J. Zhou, Z. Sun, M. Chen, J. Wang, W. Qiao, D. Long, L. Ling, Adv. Funct. Mater. 2016, 26,5368 .

[14] L. Zhang, J. Wu, Y. Wang, Y. Long, N. Zhao, J. Xu, J. Am. Chem. Soc. 2012, 134, 9879.

[15] L. Zhang, Z. Zhang, P. Wang, NPG Asia Materials 2012, 4, e8.

[16] H. Zhu, D. Chen, N. Li, Q. Xu, H. Li, J. He, J. Lu, Adv. Funct. Mater. 2015, 25, 597.

[17] Z. Dang, L. Liu, Y. Li, Y. Xiang, G. Guo, ACS Appl. Mater. Interfaces 2016, 8, 31281.

[18] W. Zhang, F. Liu, G. Liu, W. Gan, M. Zhang, H. Yu, X. Di, Y. Wang, C. Wang, Adv. Mater. Interfaces 2016, 3, 1600100.

[19] J. Jiang, Q. Zhang, X. Zhan, F. Chen, ACS Sustainable Chem. Eng. 2017, 5, 10307.

[20] Z. Lei, G. Zhang, Y. Deng, C. Wang, Appl. Surf. Sci. 2017, 416, 798.

[21] Z. Lei, G. Zhang, Y. Deng, C. Wang, ACS Appl. Mater. Interfaces 2017, 9, 8967.

[22] D. H. Kim, M. C. Jung, S. H. Cho, S. H. Kim, H. Y. Kim, H. J. Lee, K. H. Oh, M. W. Moon, Sci. Rep. 2015, 5, 12908.

[23] H. Zhu, S. Yang, D. Chen, N. Li, Q. Xu, H. Li, J. He, J. Lu, Adv. Mater. Interfaces 2016, 3,1500683 .

[24] T. Sun, G. Wang, L. Feng, B. Liu, Y. Ma, L. Jiang, D. Zhu, Angew. Chem. Int. Ed. 2004, $116,361$.

[25] R. Ou, J. Wei, L. Jiang, G. P. Simon, H. Wang, Environ. Sci. Technol. 2016, 50, 906.

[26] L. Hu, S. Gao, X. Ding, D. Wang, J. Jiang, J. Jin, L. Jiang, ACS Nano 2015, 9, 4835.

[27] B. Xue, L. Gao, Y. Hou, Z. Liu, L. Jiang, Adv. Mater. 2013, 25, 273.

[28] C. L. Zhang, F. H. Cao, J. L. Wang, Z. L. Yu, J. Ge, Y. Lu, Z. H. Wang, S. H. Yu, ACS Appl. Mater. Interfaces 2017, 9, 24857.

[29] X. Xu, B. Bai, H. Wang, Y. Suo, ACS Appl. Mater. Interfaces 2017, 9, 6424. 


\section{WILEY-VCH}

[30] L. Han, Y. Zhang, X. Lu, K. Wang, Z. Wang, H. Zhang, ACS Appl. Mater. Interfaces 2016, 8, 29088.

[31] R. Li, L. Zhang, L. Shi, P. Wang, ACS Nano 2017, 11, 3752.

[32] Y. Liu, S. Yu, R. Feng, A. Bernard, Y. Liu, Y. Zhang, H. Duan, W. Shang, P. Tao, C. Song, T. Deng, Adv. Mater. 2015, 27, 2768.

[33] H. Ghasemi, G. Ni, A. M. Marconnet, J. Loomis, S. Yerci, N. Miljkovic, G. Chen, Nat. Commun. 2014, 5, 4449.

[34] L. Shi, Y. Wang, L. Zhang, P. Wang, J. Mater. Chem. A 2017, 5, 16212.

[35] L. Zhang, B. Tang, J. Wu, R. Li, P. Wang, Adv. Mater. 2015, 27, 4889.

[36] R. Martínez-Palou, M. d. L. Mosqueira, B. Zapata-Rendón, E. Mar-Juárez, C. BernalHuicochea, J. de la Cruz Clavel-López, J. Aburto, J. Petrol. Sci. Eng. 2011, 75, 274.

[37] H. Lee, S. M. Dellatore, W. M. Miller, P. B. Messersmith, Science 2007, 318, 426.

[38] H.-C. Yang, R. Z. Waldman, M.-B. Wu, J. Hou, L. Chen, S. B. Darling, Z.-K. Xu, Adv. Funct. Mater. 2018, 1705327.

[39] W. Zhang, Z. Pan, F. K. Yang, B. Zhao, Adv. Funct. Mater. 2015, 25, 1588.

[40] W. Zhang, Y. Zhou, K. Feng, J. Trinidad, A. Yu, B. Zhao, Adv. Electron. Mater. 2015, 1, 1500205.

[41] F. Li, M. Du, Q. Zheng, ACS Nano 2016, 10, 2910.

[42] Y. Liu, Z. Liu, Y. Liu, H. Hu, Y. Li, P. Yan, B. Yu, F. Zhou, Small 2015, 11, 426.

[43] Q. Zhu, Q. Pan, ACS Nano 2014, 8, 1402.

[44] Y. Li, Y. Zhao, X. Lu, Y. Zhu, L. Jiang, Nano Research 2016, 9, 2034.

[45] S. Gao, J. Sun, P. Liu, F. Zhang, W. Zhang, S. Yuan, J. Li, J. Jin, Adv. Mater. 2016, 28, 5307.

[46] J. Chang, Y. Shi, M. Wu, R. Li, L. Shi, Y. Jin, W. Qing, C. Tang, P. Wang, J. Mater. Chem. A 2018, DOI: 10.1039/C8TA00779A. 


\section{WILEY-VCH}

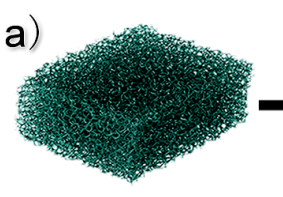

MS substrate

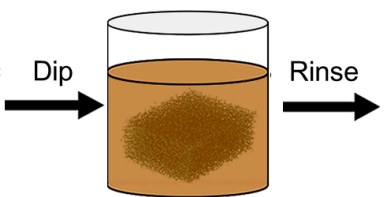

1) Dopamine solution

2) Pyrrole solution

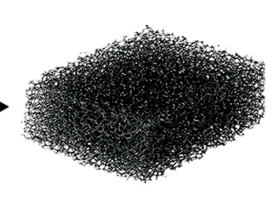

PPy@MS

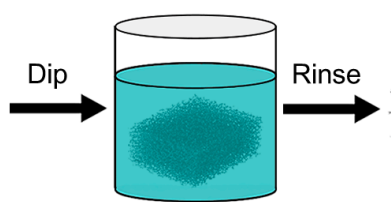

3) Dopamine solution 4) NIPAm solution

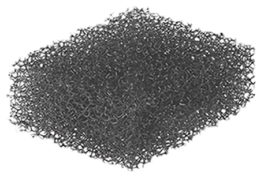

PNIPAm/PPy@MS
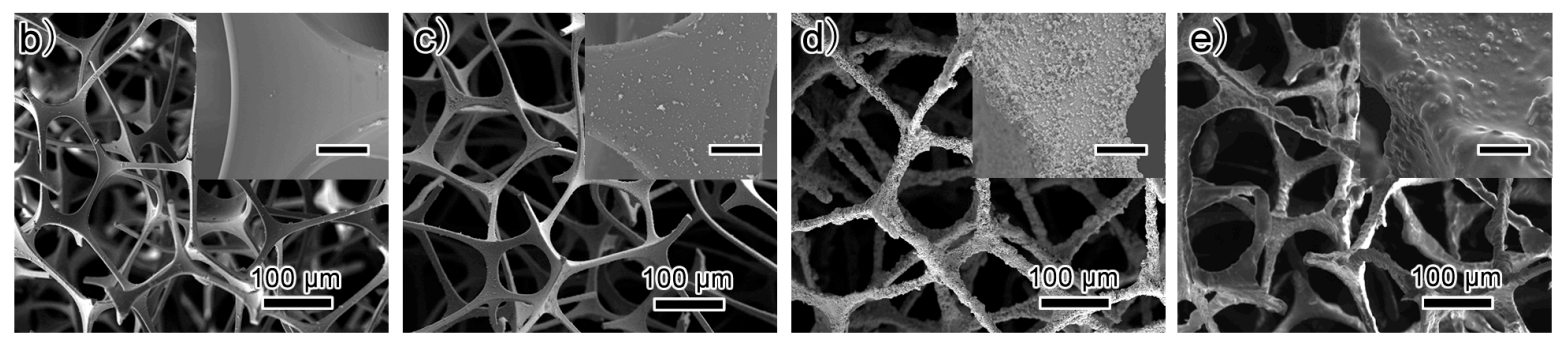

Figure 1. (a) Schematic illustration of the fabrication process of PNIPAm/PPy@MS. 1)-4) in (a) represent the sequential polymerization to form PDA, PPy, PDA and PNIPAm layer on MS substrate, respectively. SEM images of (b) original MS, (c) PDA@MS, (d) PPy@MS, and (e) PNIPAm/PPy@MS. The insets in (b-e) show the corresponding magnified SEM images. The scale bars in the insets are all $10 \mu \mathrm{m}$.

$40{ }^{\circ} \mathrm{C}$
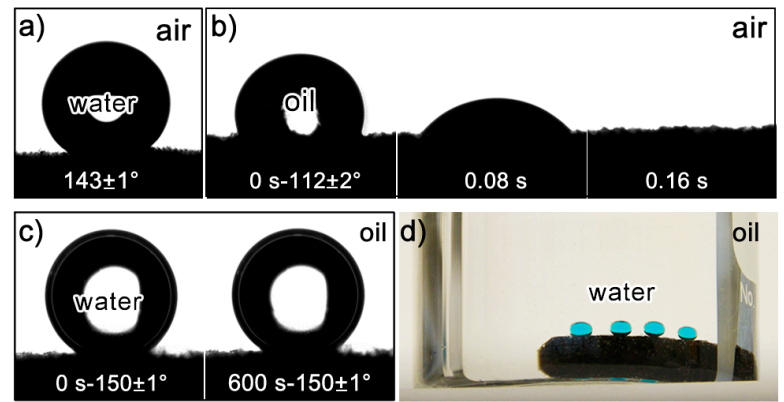

$22{ }^{\circ} \mathrm{C}$

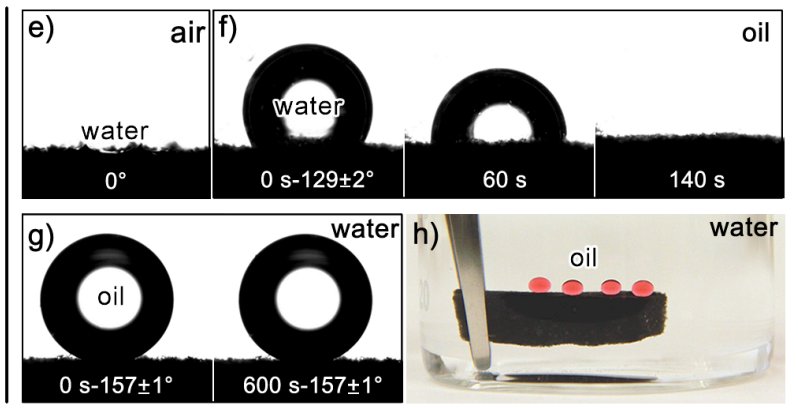

Figure 2. Wettability of the PNIPAm/PPy@MS at the temperature of (a-d) $40{ }^{\circ} \mathrm{C}$, and (e-h) $22{ }^{\circ} \mathrm{C}$. Contact angle images (a-c, e-g) and digital images $(\mathrm{d}, \mathrm{h})$ of the PNIPAm/PPy@MS, illustrating the wetting of water in air (a, e) and under oil (c, d, f), and the wetting of oil in air (b) and under water (g, h). Note: the oil in (b-d) and (f) was mineral oil (density: $0.84 \mathrm{~g} / \mathrm{mL}$, viscosity: $107 \mathrm{mPa} \mathrm{s}$ ), and the oil in (g) and (h) was silicone oil AP 100 (density: $1.06 \mathrm{~g} / \mathrm{mL}$, viscosity: $160 \mathrm{mPa}$ ). The water droplets in (d) were stained by methylene blue and the oil droplets in (h) were stained by Oil Red O.
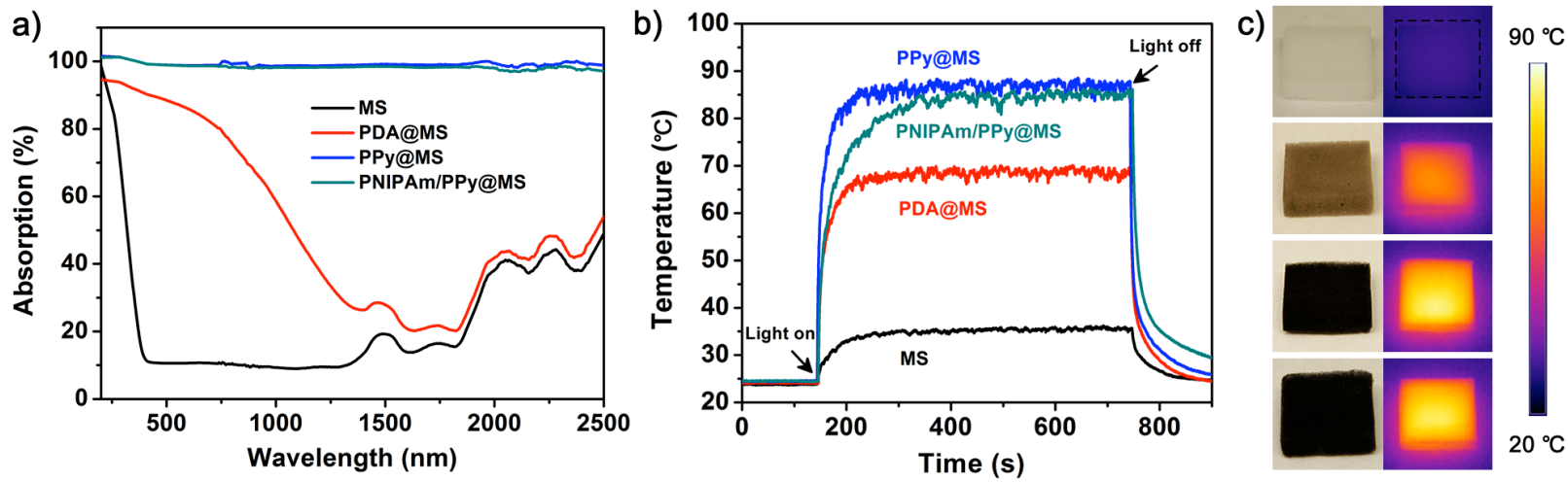

Figure 3. (a) UV-vis-NIR absorption spectra and (b) time-dependent top surface temperature changes of original MS, PDA@MS, PPy@MS, and PNIPAm/PPy@MS in response to 1000 


\section{WILEY-VCH}

$\mathrm{W} \mathrm{m}^{-2}$ light irradiation. (c) Digital images (left) and IR thermal images (right) of original MS, PDA@MS,PPy@MS, and PNIPAm/PPy@MS.

a)
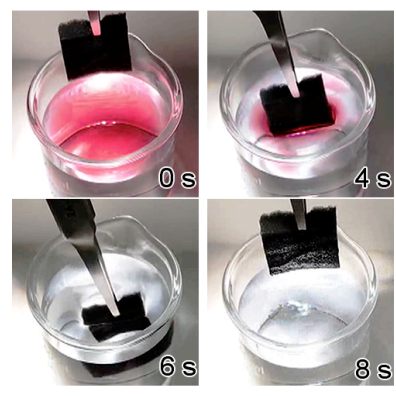

d)

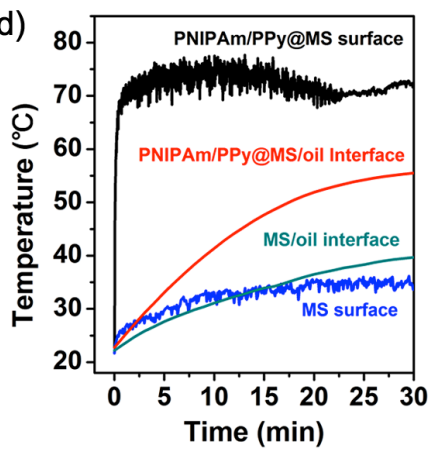

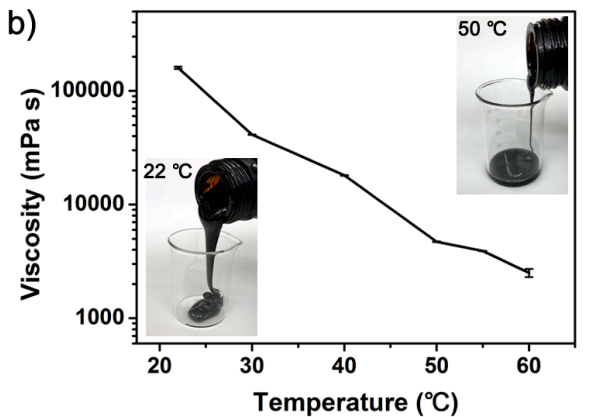

c)

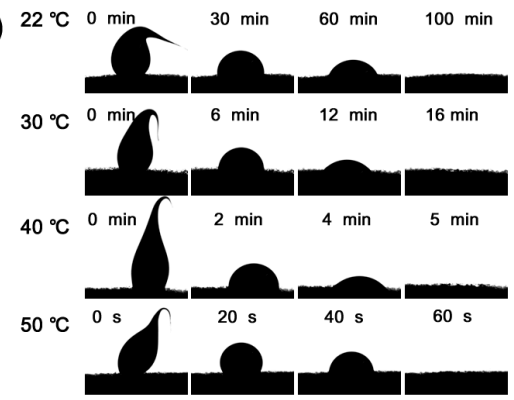

e)

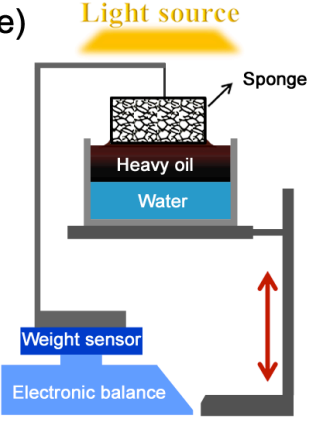

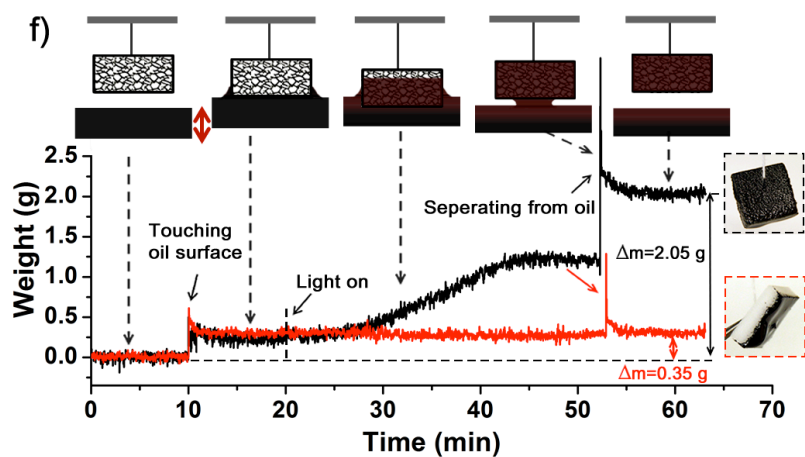

Figure 4. (a) Absorption of mineral oil with PNIPAm/PPy@MS under 1000 W m ${ }^{-2}$ light irradiation. (b) The bitumen viscosity as a function of temperature. (c) Permeating behavior of bitumen droplets on the surface of PNIPAm/PPy@MS at different temperatures. (d) The temperatures at the sponge top surface and sponge bottom/oil interface of the original MS and PNIPAm/PPy@MS placed on top of the bitumen under $1000 \mathrm{~W} \mathrm{~m}^{-2}$ light irradiation. (e) Schematic illustration of the lab-made device for the measurement of the heavy oil absorption. (f) The stage-wise process of the bitumen absorption with original MS (red line) and PNIPAm/PPy@MS (black line) under $1000 \mathrm{~W} \mathrm{~m}^{-2}$ light irradiation. The insets (right) are the digital images of PNIPAm/PPy@MS and MS after bitumen absorption test.

a)

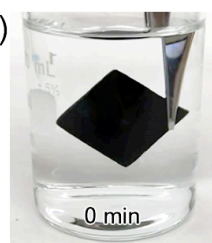

b)

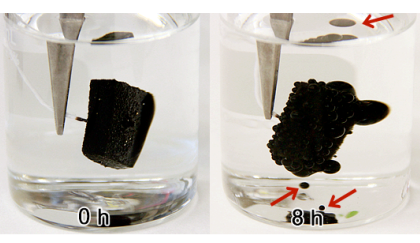

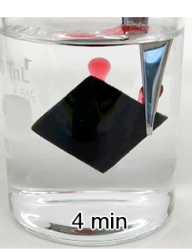

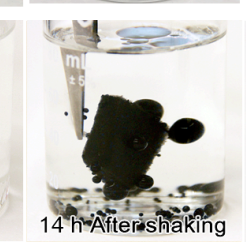

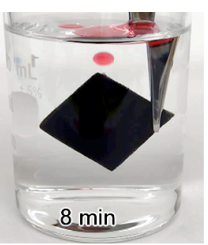
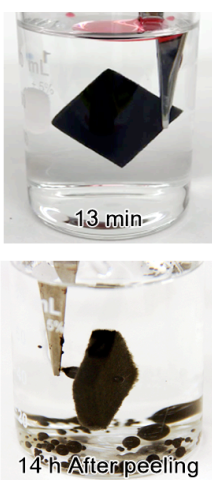

c)

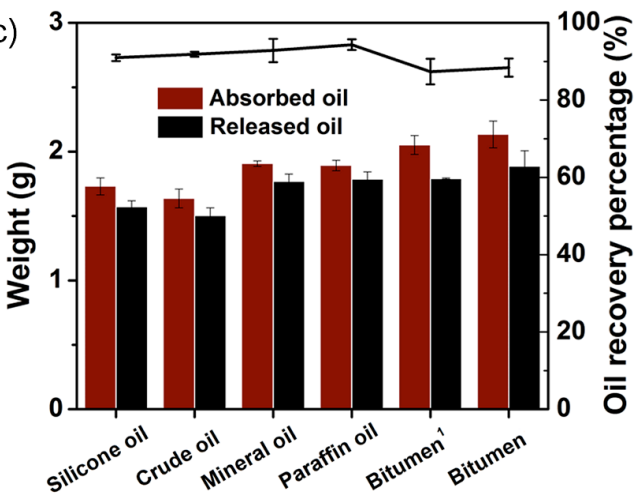

Figure 5. Desorption of (a) mineral oil and (b) bitumen from PNIPAm/PPy@MS underwater at $22{ }^{\circ} \mathrm{C}$. (c) Oil absorption and desorption capacities of the PNIPAm/PPy@MS. 


\section{WILEY-VCH}

\section{The table of contents entry}

Melamine sponges with the integrated sunlight induced photo-thermal effect and thermoresponsive wettability rapidly absorb highly viscous oil solely driven by sunlight and the absorbed oil voluntarily comes out of the sponge underwater at room temperature without any intervention.

Keywords: sunlight, photo-thermal effect, switchable wettability, heavy oil spill, passive oil release

Mengchun Wu, Yusuf Shi, Jian Chang, Renyuan Li, Chisiang Ong and Peng Wang*

Sunlight Induced Rapid Oil Absorption and Passive Room-Temperature Release: An Effective Solution toward Heavy Oil Spill Cleanup

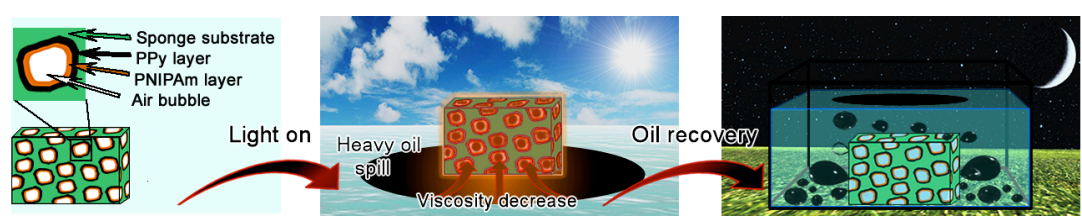




\section{WILEY-VCH}

Copyright WILEY-VCH Verlag GmbH \& Co. KGaA, 69469 Weinheim, Germany, 2016.

\section{Supporting Information}

Sunlight Induced Rapid Oil Absorption and Passive Room-Temperature Release: An Effective Solution toward Heavy Oil Spill Cleanup

Mengchun Wu, Yusuf Shi, Jian Chang, Renyuan Li, Chisiang Ong and Peng Wang*
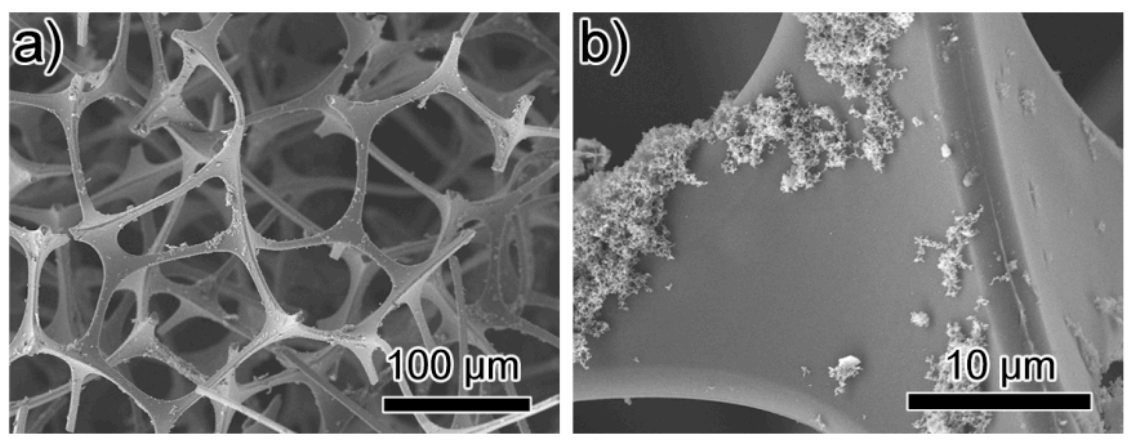

Figure S1. (a, b) SEM images of PPy coated MS without PDA layer.

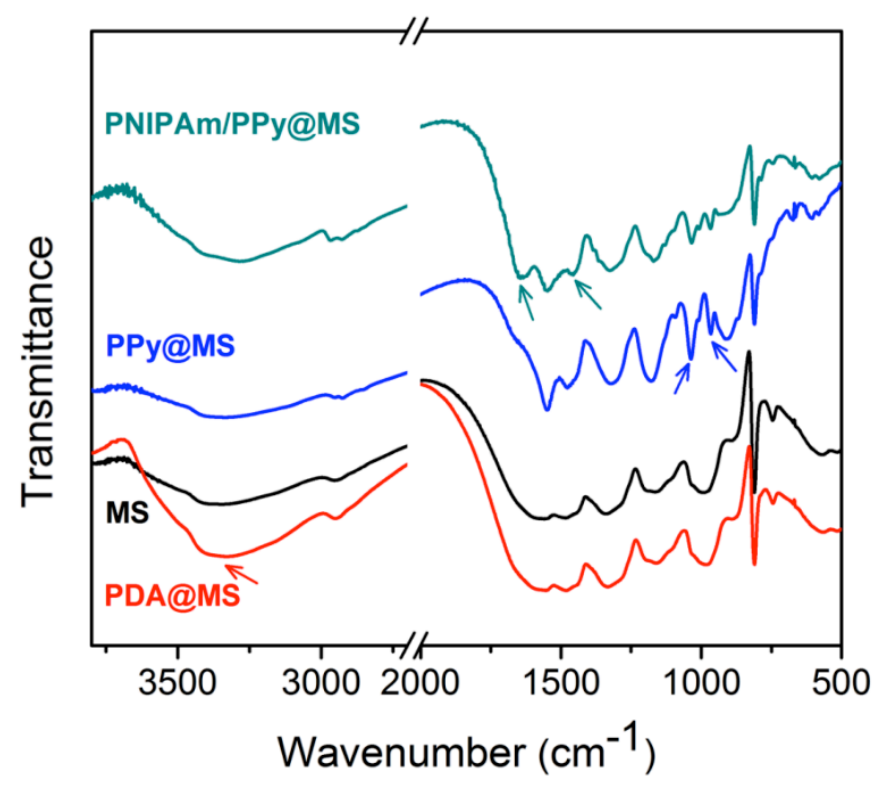

Figure S2. FTIR spectra of MS, PDA@MS, PPy@MS, and PNIPAm/PPy@MS. 


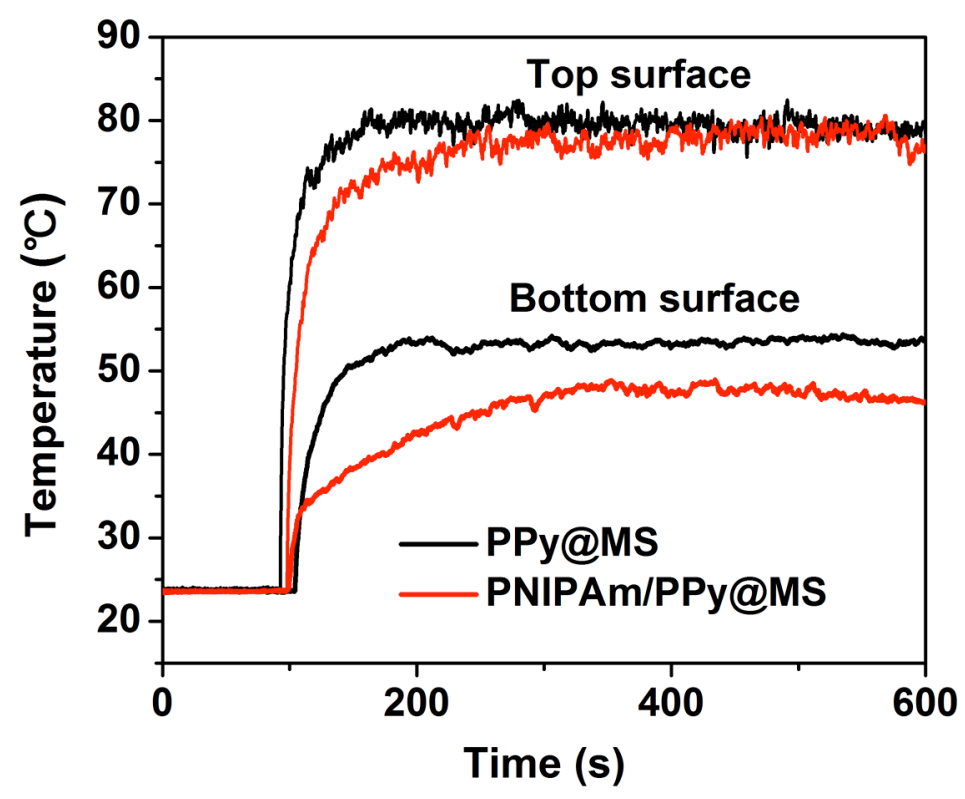

Figure S3. Time-course of the temperature of the top surface and bottom surface of PPy@MS (black curves) and PNIPAm/PPy@MS (red curves).

To estimate the thermal conductivity of PPy@MS and PNIPAm/PPy@MS, the samples with the thickness of $5.0 \mathrm{~mm}$ were prepared and placed into a size matched hole made in the thermally insulating polystyrene foam. The top surfaces of the sponges were exposed to the simulated solar light with the light intensity of $1000 \mathrm{~W} \mathrm{~m}^{-2}$, and IR camera was used to detect the temperatures of the top surface and the bottom surface of the sponges. As shown in Figure S3, both the top and bottom surfaces of all sponges reached the steady state temperature after $200 \mathrm{~s}$ under light irradiation. The steady state temperatures of the top surface and bottom surface of PPy@MS were $\sim 79.4{ }^{\circ} \mathrm{C}$ and $\sim 53.5{ }^{\circ} \mathrm{C}$, respectively. The steady state temperatures of the top surface and bottom surface of PNIPAm/PPy@MS were $\sim 78.0{ }^{\circ} \mathrm{C}$ and $\sim 47.5{ }^{\circ} \mathrm{C}$, respectively. The temperature difference between the top and bottom surfaces for PPy@MS and PNIPAm/PPy@MS were $25.9{ }^{\circ} \mathrm{C}$ and $30.5{ }^{\circ} \mathrm{C}$, respectively. By using the Fourier equation: $\mathrm{Q}=\mathrm{k} \Delta \mathrm{T} / \Delta \mathrm{X} \quad$ Equation $\mathrm{S} 1$

Where $\mathrm{Q}$ is the heat flux $\left(1000 \mathrm{~W} \mathrm{~m}^{-2}\right), \mathrm{k}$ is the thermal conductivity, and $\Delta \mathrm{T} / \Delta \mathrm{X}$ is the temperature gradient across the sample. Then the thermal conductivity of PPy@MS and PNIPAm/PPy@MS were calculated to be $\sim 0.19 \mathrm{~W} \mathrm{~m}^{-1} \mathrm{~K}^{-1}$ and $\sim 0.16 \mathrm{~W} \mathrm{~m}^{-1} \mathrm{~K}^{-1}$, respectively. 


\section{WILEY-VCH}

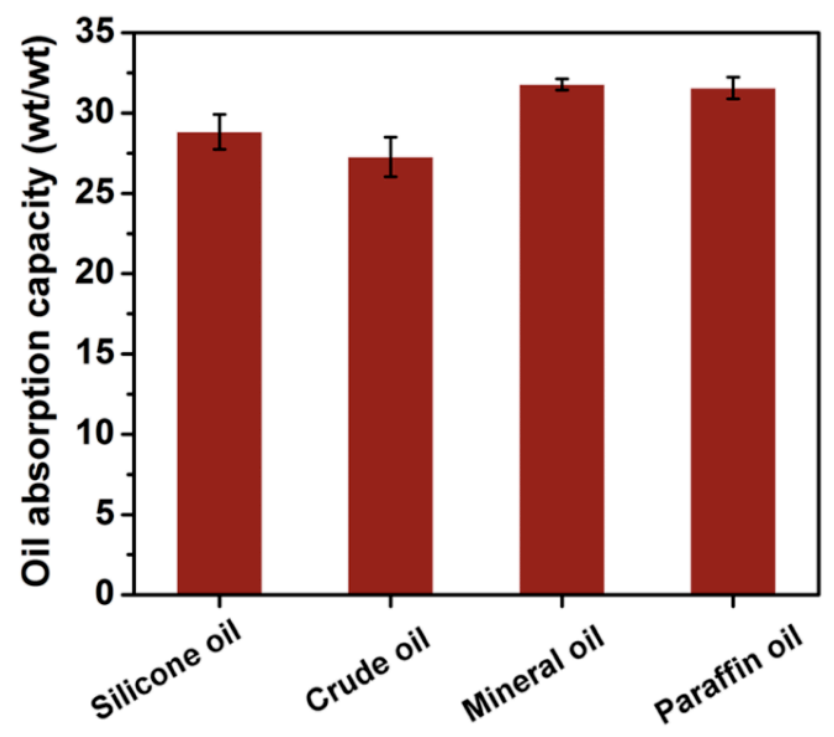

Figure S4. The oil absorption capacity of PNIPAm/PPy@MS.
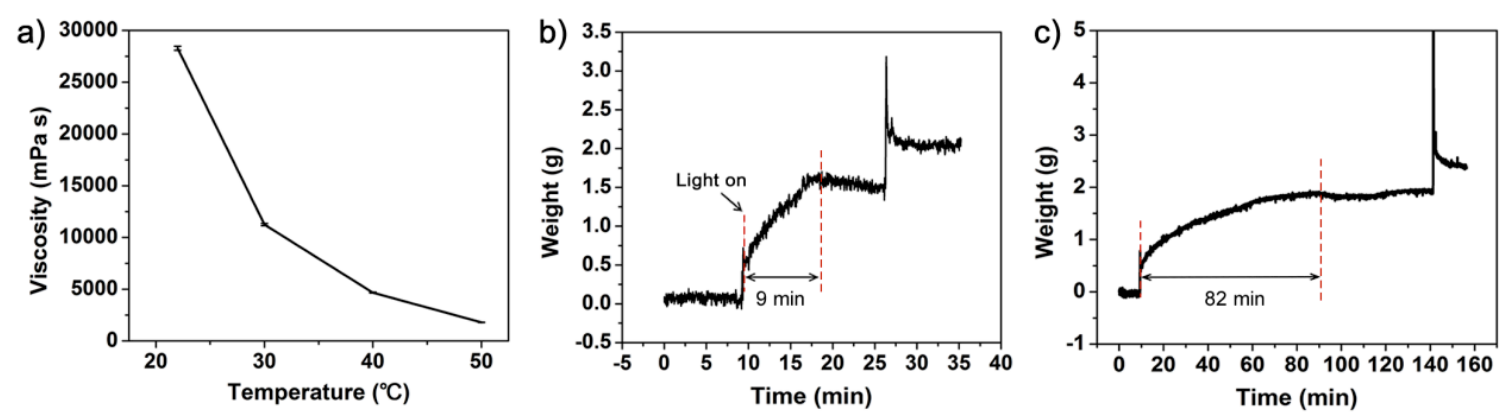

Figure S5. (a) The bitumen ${ }^{1}$ viscosity as a function of temperature. The stage-wise process of the bitumen ${ }^{1}$ absorption with PNIPAm/PPy@MS under $1000 \mathrm{~W} \mathrm{~m}^{-2}$ light illumination (b) and without light illumination (c).

a)

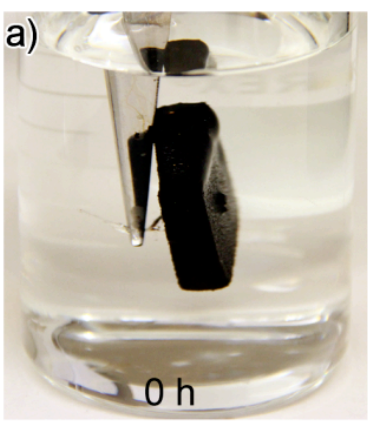

b)

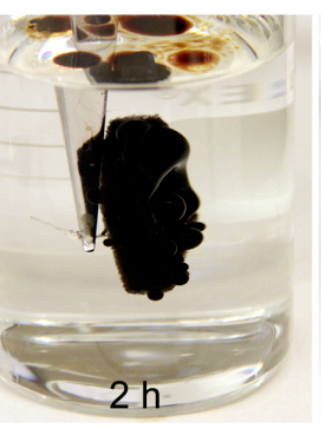

c)

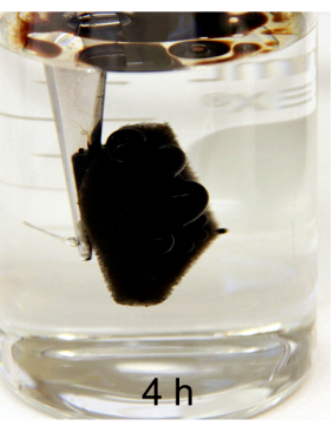

d)

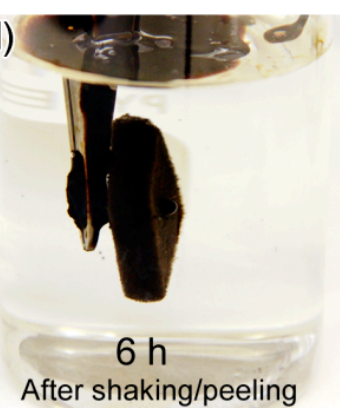




\section{WILEY-VCH}

Figure S6. Desorption process of bitumen ${ }^{1}$ from PNIPAm/PPy@MS under water at $22{ }^{\circ} \mathrm{C}$.

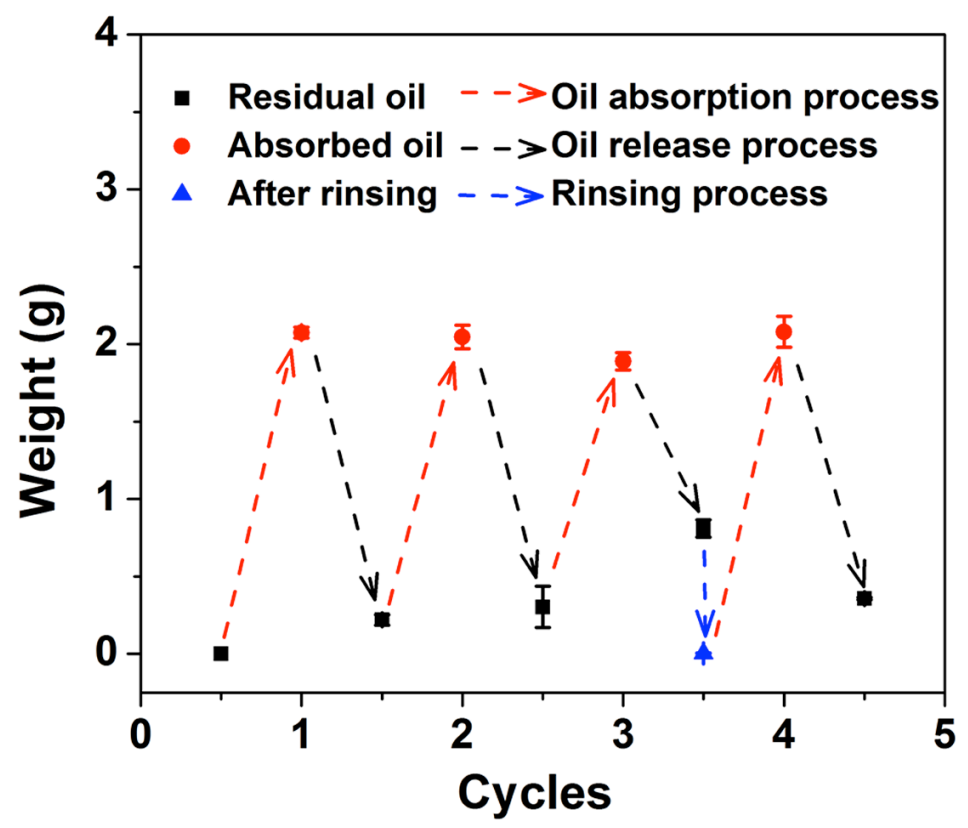

Figure S7. Repeated bitumen absorption and desorption process of PNIPAm/PPy@MS.

a)

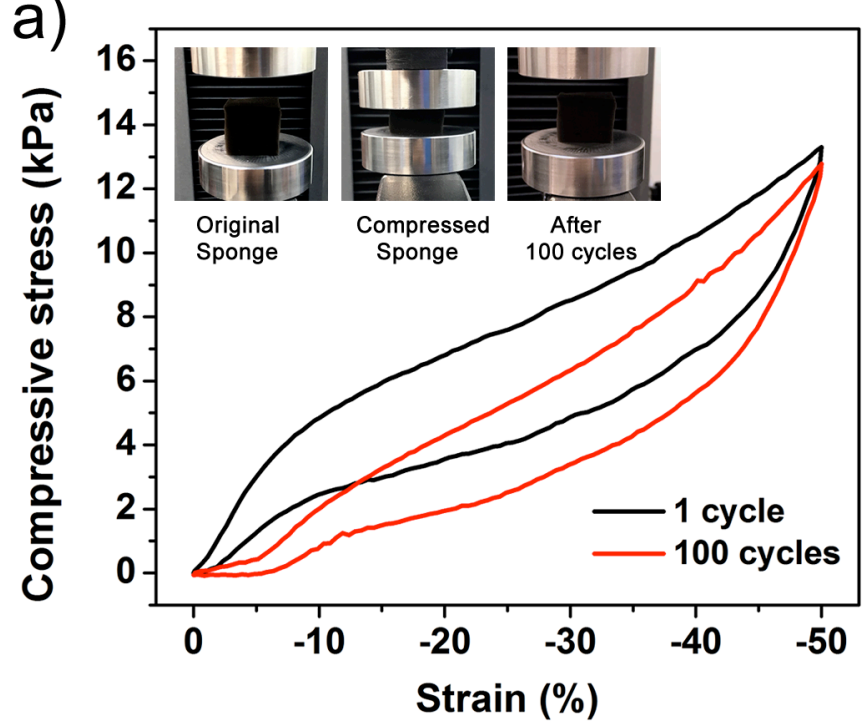

b)

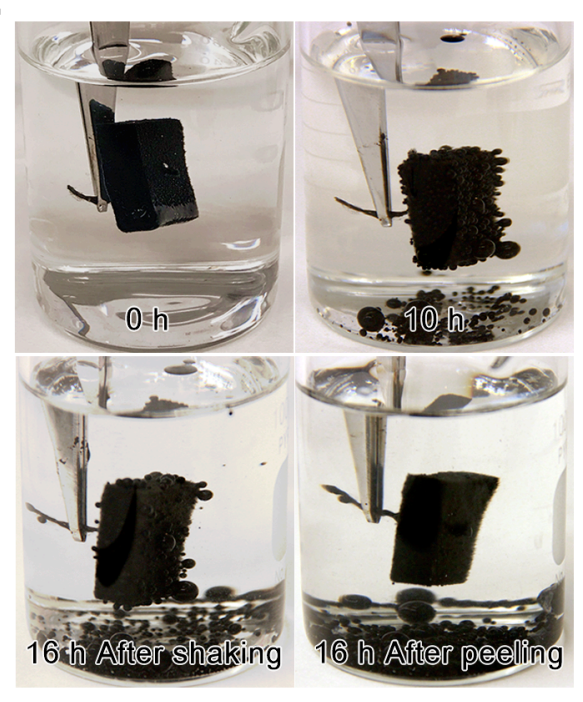

Figure S8. (a) Compressive stress-strain curves of PNIPAm/PPy@MS $\left(2 \times 2 \times 2 \mathrm{~cm}^{3}\right)$ and photographs of the PNIPAm/PPy@MS before and after compression test. (b) Desorption of bitumen from compressed PNIPAm/PPy@MS $\left(2 \times 2 \times 0.5 \mathrm{~cm}^{3}\right)$ underwater at $22{ }^{\circ} \mathrm{C}$. 


\section{WILEY-VCH}

Table S1. The parameters of the oils $\left(22^{\circ} \mathrm{C}\right)$ used in the oil absorption and desorption processes.

\begin{tabular}{lccc}
\hline Oils & Viscosity $(\mathrm{mPa} \mathrm{s})$ & Density $(\mathrm{g} / \mathrm{mL})$ & Oil desorption time \\
\hline Silicone oil & 13 & 0.93 & $23 \mathrm{~min}$ \\
Crude oil & 31 & 0.90 & $50 \mathrm{~min}$ \\
Mineral oil & 107 & 0.84 & $13 \mathrm{~min}$ \\
Paraffin oil & 219 & 0.85 & $17 \mathrm{~min}$ \\
Bitumen $^{1}$ & $2.83 \times 10^{4}$ & 0.92 & $6 \mathrm{~h}$ \\
Bitumen $^{1.60 \times 10^{5}}$ & 0.99 & $14 \mathrm{~h}$ \\
\hline
\end{tabular}

\section{Caption for Supporting Movie}

Movie S1. The desorption process of mineral oil from PNIPAm/PPy@MS under water at $22^{\circ} \mathrm{C}$. 